\title{
Movimentos Sociais Rurais no Brasil: o estado da arte $^{1}$
}

\author{
Edna Lopes Miranda² e Ana Louise Carvalho Fiúza ${ }^{3}$
}

Resumo: Os movimentos sociais rurais têm sido foco de vários estudos que apontam para o seu papel ativo na luta por direitos dos grupos excluídos dentro da sociedade brasileira. Através de ações coletivas, agem como resistência à exclusão e provocam novas dinâmicas sociais no campo. Partindo da concepção teórica de novos movimentos sociais apresentada por Alain Touraine, este artigo se propôs a mapear e a discutir o estado da arte referente a teses e dissertações sobre movimentos sociais rurais. Adotamos os períodos compreendidos entre 2002 a 2014 para o mapeamento das teses e dissertações e 1980 a 2015 para as análises das temáticas relativas aos movimentos sociais rurais. Utilizou-se, para a realização das análises, o software Alceste (Análise Lexical por Contexto de um Conjunto de Segmentos de Texto). Os resultados mostraram que o período posterior a 2003 marcou a passagem do viés combativo para a rotinização dos movimentos sociais, tendo as contestações sociais se deslocado do mundo do trabalho para a vida cotidiana, com uma pluralidade de demandas materiais e simbólicas que giraram em torno do reconhecimento de identidades e do modo de vida camponês, evidenciando-se a politização dos costumes e práticas relativos ao modo de vida tradicional.

Palavras-chaves: Movimentos sociais, estado da arte, rural.

Abstract: The rural social movements have been the focus of several studies that point to its active role in the struggle for rights to excluded groups within Brazilian society. Through the collective actions, act as exclusion of resistance and provoke new social dynamics in the field. Starting from the theoretical concept of social movements of Alain Touraine, this paper set out mapping and discussing the state of the art in relation to theses and dissertations on rural social movements. The period adopted to map the theses and dissertations was from 2002 to 2014 and from 1980 to 2015 to the thematic analysis related to the social rural movements. The Alceste software (Analyse Lexicale par Contexte d'un Ensemble de Segments de Texte ) was used for the analysis. The results showed that

DOI - http://dx.doi.org/10.1590/1234-56781806-94790550107

1. Data de submissão: 29 de outubro de 2015. Data de aceite: 31 de outubro de 2016.

2. Doutoranda do Programa de Pós-Graduação em Extensão Rural, Departamento de Economia Rural, Universidade Federal de Viçosa (UFV), Viçosa, MG, Brasil. E-mail: edna.miranda04@hotmail.com

3. Professora do Programa de Pós-graduação em Extensão Rural, Departamento de Economia Rural, Universidade Federal de Viçosa (UFV), Viçosa, MG, Brasil. E-mail: louisefiuza@ufv.br 
the period after 2003 highlighted the passage of combative bias for the routinization of social movements, once the social contestations changed from the work life to the everyday life, with a plurality of material and symbolic demand surrounding the recognition of identities and the rural people life styles. This highlights the politics of the customs and practices related to the traditional life style.

Key-words: Social movements, state of the art, rural.

Classificação JEL: Z1, Z19.

\section{Introdução}

Vários estudos têm apontado para o papel ativo dos movimentos sociais na luta por direitos e garantias de grupos excluídos dentro da sociedade brasileira. A articulação de ações coletivas, que agem como resistência à exclusão e que provocam novas dinâmicas sociais, seja na cidade ou no campo, vem se reformulando e ganhando novos contornos sociais (NAVARRO, 1996; PAOLI e TELLES, 2000; PICOLOTTO, 2007).

As ações e estratégias de resistência dos movimentos sociais rurais vêm criando condições para que as suas demandas sejam publicizadas e cheguem até as instâncias decisórias do Estado. Os movimentos sociais trazem, na sua gênese, a característica de contestação da realidade na qual estão inseridos e se organizam para promover a ruptura de uma situação de ausência de direitos.

Este artigo analisará, especificamente, a emergência dos movimentos sociais rurais, no Brasil, enfatizando as transformações sociais no campo que têm incidido tanto através da luta por terra quanto nas valorações estabelecidas aos trabalhadores rurais (TOURAINE, 2003; MELUCCI, 2001). A trajetória dos atores sociais que vieram a constituí-los é longa e permeada de conflitos sociais e políticos, o que requer pesquisas mais aprofundadas. É com base nestas reflexões que o presente estudo se propôs a mapear e discutir o estado da arte das teses e dissertações sobre os movimen- tos sociais rurais no período de 2002 a 2014, a fim de identificar as problemáticas, metodologias e referenciais teóricos que estão mais presentes nas investigações sobre esta temática.

Este estudo tem o objetivo de apresentar o estado da arte em torno da produção acadêmica discente dos programas nacionais de pós-graduação stricto sensu, expressa em teses de doutoramento e dissertações de mestrado, a fim de analisar a percepção que a academia vem manifestando acerca dos movimentos sociais no campo, no Brasil, especificamente, na última década. Tal demarcação temporal foi adotada em função dos anos 2000 manifestarem características mais adaptativas do que contestatórias em relação ao status quo vigente.

\section{Fundamentação teórica}

Segundo a teoria dos Novos Movimentos Sociais, ações coletivas estruturam-se a partir de repertórios criados sobre temas e problemas em situações de conflito e disputa. Segundo Melucci (2001), as ações coletivas são produzidas por orientações intencionais desenvolvidas dentro de um campo de oportunidades e restrições. Desta maneira, a formação de ações coletivas depende da mediação das capacidades cognitivas dos atores individuais e de suas estratégias. Neste sentido, Touraine (2006, p. 175) acrescenta 
que os movimentos sociais são "atores de um conflito, agindo com outros atores organizados, que lutam pelo uso social dos recursos culturais e materiais, aos quais os dois campos atribuem, tanto um com o outro, uma importância central". Também postula que os movimentos sociais apresentam um marco característico, na medida em que apontam diretamente para o sistema político, e tratam de construir uma identidade que lhes permita atuar sobre si mesmos e sobre a sociedade como um todo, por meio de práticas, valores e normas sociais que constituem um sistema de conhecimento.

Os movimentos sociais rurais no Brasil tiveram grande proeminência na década de 1950 com as Ligas Camponesas, notadamente no Nordeste, caíram na clandestinidade nos anos 1960 e 1970 e, nos anos 1980, voltaram a se manifestar, contando, sobremaneira, com a atuação da igreja católica e de partidos de esquerda, como o PT (Partido dos Trabalhadores). Como afirma Grybowsky (1994), os problemas vividos pela maioria da população rural, em particular, os trabalhadores assalariados, os camponeses e as suas famílias, estavam vinculados à exploração e à marginalização decorrente da modernização agrícola no campo.

A partir dos anos 1970, o campo, no Brasil, sofreu as consequências deste desenvolvimento excludente, evidenciado na degradação dos recursos naturais, na concentração fundiária, no êxodo rural, nas transformações dos sistemas de produção e de relações sociais. Neste contexto, os diversos atores sociais, como trabalhadores rurais, boias-frias, mulheres, jovens e pequenos produtores rurais, começaram a se organizar, demonstrando resistência aos problemas decorrentes deste processo de modernização. Neste contexto, Martins (1989) defende que a resistência camponesa significa mais do que uma luta pela terra, uma luta pela preservação de um modo de vida, baseado no trabalho coletivo do mutirão, na preservação da agricultura familiar e na sociabilidade entre parentes, compadres e vizinhos, uma alternativa real à degradação e à miséria.

Segundo o sociólogo Rudá Ricci (2005), boa parte dos movimentos sociais rurais tem uma história tortuosa, uma vez que o ideal que prevaleceu até fins da década de 1980, de instaurar novas práticas políticas e sociais, foi se amalgamando ao processo de aparelhamento do Estado por via partidária. Desta forma, muitos movimentos sociais se institucionalizaram via partidos políticos. Para Cohen e Arato (2000), ao se institucionalizarem, os movimentos sociais se racionalizam, buscando proteger seus direitos e se abastecer com novas e criativas forças sociais. Neste sentido, para estes autores, os movimentos sociais têm uma lógica dual, por um lado, defensiva e, por outro, ofensiva. No âmbito defensivo, situa-se a formação de identidades, de base local, que agem sobre a consciência e a cultura dos grupos. Já em seu aspecto ofensivo, estão as estratégias no jogo de poder entre atores externos, visando se incluir institucionalmente no sistema político e intervir nas políticas públicas.

Os movimentos sociais possuem a habilidade de combinar uma pluralidade de formas de ação que vão de estratégias contenciosas e disruptivas, como os protestos públicos, passeatas e ocupações, até ações formais de encaminhamento de demandas. O conjunto dessas ações e formas de resistência é contingente e dinamizado pela relação com a sociedade civil e com o Estado em cada contexto histórico específico. No que diz respeito aos movimentos sociais rurais, estes têm intensificado a sua participação nas disputas que envolvem a luta pela terra e o controle social das políticas públicas relacionadas ao campo, buscando fortalecer a agricultura familiar. Contudo, nas últimas décadas os movimentos sociais rurais apresentam-se com outras concepções e práticas, mais próximas do cotidiano, dos costumes e dos desejos daqueles que vivem da agricultura.

\section{Metodologia}

Os estudos relativos ao estado da arte permitem, num recorte temporal definido, sistematizar um determinado campo de conhecimento, reconhecer os principais resultados da investigação, identificar temáticas e abordagens dominantes e 
emergentes, bem como lacunas e campos inexplorados abertos à pesquisa futura. Segundo Biancha et al. (2004), é importante avaliar as continuidades e descontinuidades teóricas e metodológicas, o quanto se redunda ou se avança na produção de saber, para se evitar a cristalização do conhecimento e provocar um constante movimento para avançar na compreensão do objeto de estudo.

Esta pesquisa tem um caráter qualitativo, pois trata de um "universo de significados, valores, motivos, crenças e aspirações, de processos e fenômenos que não podem ser reduzidos à operacionalização de variáveis" (MINAYO, 1996, p. 22). Para tanto, optou-se pela pesquisa do tipo "estado da arte" em virtude de esta propiciar a realização de um mapeamento das produções acadêmicas e científicas, considerando o período de 2002 a 2014. A escolha por este recorte temporal justifica-se por se tratar de um período marcado por características mais adaptativas do que contestatórias em relação às políticas implementadas pelo Estado.

De acordo com Ferreira (2002, p. 1), as pesquisas denominadas estado da arte "parecem trazer em comum o desafio de mapear e de discutir uma certa produção acadêmica em diferentes campos do conhecimento". De tal modo, estes estudos são reconhecidos por realizarem uma metodologia de caráter descritivo e inventariante da produção acadêmica e científica sobre o tema que se busca investigar. Ao tomar os movimentos sociais rurais como campo investigativo nas pesquisas e produções acadêmicas pretende-se, além da descrição das mesmas, detectar quais abordagens conceituais são apresentadas pelas pesquisas e como tem se apresentado o debate sobre os movimentos sociais rurais nestes estudos. São, portanto, estes questionamentos que fazem do estado da arte um campo metodológico de abrangência e significância nas pesquisas acadêmicas.

Para a realização do presente estudo, os seguintes procedimentos foram adotados: $1^{\text {o }}$ ) levantamento de dados junto ao banco de teses da Coordenadoria de Aperfeiçoamento de Pessoal de Nível Superior (Capes), que disponibiliza, desde
1987, as referências bibliográficas e resumos de teses e dissertações defendidas nos programas de pós-graduação stricto sensu; $2^{\underline{o}}$ ) levantamento de dados junto aos sítios eletrônicos das bibliotecas universitárias, especialmente o Banco Digital de Teses e Dissertações (BDTD); $3^{\circ}$ ) consulta à lista de referências bibliográficas das teses e dissertações adquiridas, pois muitas delas indicavam outros trabalhos defendidos na área. Realizou-se, ainda, uma busca avançada por meio da utilização dos termos "ação coletiva", "espaço rural" e "movimentos sociais", considerando-se o recorte temporal de 2002 a 2014.

Realizadas estas etapas, foram mapeadas 126 produções (80 dissertações e 46 teses) relativas aos movimentos sociais rurais. As mesmas foram analisadas pelos títulos, palavras-chaves e resumos. Desta forma, procedeu-se à leitura dos 126 resumos, o que incluiu a identificação do objeto de estudo, a problemática da pesquisa, a identificação das técnicas empreendidas na coleta de dados, o registro dos principais referenciais teóricos presentes e a identificação das conclusões. Neste sentido, realizou-se um estudo qualitativo de caráter exploratório com um recorte espacial e temporal da amostra, com 126 resumos de dissertações e teses que analisavam os movimentos sociais rurais.

Para complementar a análise dos dados apreendidos através dos resumos das dissertações e teses, utilizou-se o software Alceste (Análise Lexical por Contexto de um Conjunto de Segmentos de Texto), desenvolvido, na França, por M. Reinert (1990). Este programa, além de permitir uma análise lexical quantitativa que considera a palavra como unidade, também oferece a sua contextualização no corpus. Cada resumo é composto por conteúdos semânticos que formam o banco de dados ou corpus analisado pelo Alceste. Estes resultam em uma "Análise Hierárquica Descendente", a qual permite o exame das raízes lexicais e oferece os contextos em que as classes estão inseridas, de acordo com o segmento de textos do corpus da pesquisa (CAMARGO, 2005).

Na elaboração do corpus, as unidades de contexto inicial (UCIs) foram consideradas a partir 
dos 126 resumos obtidos. Em seguida, estes resumos foram separados pelas linhas de comando, contendo asteriscos que representavam as variáveis categóricas, tal como no exemplo que se segue: ${ }^{* * * *}{ }^{*} r_{-} 01{ }^{*}$ it_1 ${ }^{*}$ pp_01 ${ }^{*}$ tt_1 ${ }^{*}$ an_1, no qual a codificação atendeu à seguinte legenda: (nr) número do resumo; (it) instituição; (pp) programa de pós-graduação, (tt) temática trabalhada e (an) ano.

O principal procedimento metodológico desta pesquisa foi a identificação do objeto de estudo de cada uma das 126 dissertações e teses e, posteriormente, o agrupamento dos mesmos em áreas temáticas. A análise dos resultados foi constituída pelo corpus de 126 unidades de contexto inicial (u.c.i) que foram processadas pelo software Alceste.

\section{Resultados e discussões}

A divisão do corpus apresentou 924 unidades de contexto elementar (u.c.e), contendo 5.035 palavras ou vocábulos distintos. O diagrama que se segue faz alusão à distribuição das quatro classes referentes ao estado da arte sobre movimentos sociais rurais apreendidas a partir do recorte dos 126 resumos.

No diagrama, consta o título de cada uma das classes, seguido pelo número de u.c.e. (unidade de contexto elementar) que compõe a descrição da classe, bem como as palavras de maior associação com a referida classe, segundo o coeficiente que o mesmo obteve no teste de associação qui-quadrado. As classes, após a categorização resultante da estruturação dos discursos categorizados pelo Alceste, resultaram na organização da seguinte maneira: Classe 1 - Metodologias utilizadas nas pesquisas; Classe 2 - Demandas e lutas dos movimentos sociais rurais; Classe 3 Mulheres e movimentos sociais contemporâneos e Classe 4 - Ações socioeducativas dos movimentos sociais rurais.

\subsection{Classe 1 - Metodologias utilizadas e tipo de pesquisa}

Esta classe foi estruturada com 72 u.c.e's, correspondendo a $10 \%$ do total da amostra, o que também demonstra um significativo poder explicativo. As palavras mais importantes que surgiram nessa classe foram: entrevistas, qualitativa, observação, etnografia, método semiestruturado. Tais palavras, em conjunto com a análise dos conteúdos lexicais, refletem o percurso metodológico adotado pelos pesquisadores e mostram que a quase totalidade dos trabalhos se relaciona à pesquisa participante, ao estudo etnográfico e à abordagem qualitativa. Já as técnicas de coleta de dados foram variadas: relatos orais, entrevistas, questionários, observações, fotografias e análise de documentos. Os conteúdos apontaram, enfaticamente, para a utilização da pesquisa qualitativa nestes estudos, pois esta consegue abarcar a complexidade das relações socioespaciais presentes nos movimentos sociais rurais, suas singularidades e contradições.

Quadro 1. Diagrama das classes do estado da arte sobre movimentos sociais rurais

\begin{tabular}{|c|c|c|c|c|c|c|c|}
\hline \multicolumn{2}{|c|}{ 1- Classe } & \multicolumn{2}{|c|}{ 2- Classe } & \multicolumn{2}{|c|}{$3^{\text {a }}$ Classe } & \multicolumn{2}{|l|}{$4^{\text {a }}$ Classe } \\
\hline \multicolumn{2}{|c|}{$\begin{array}{l}\text { Metodologias } \\
\text { utilizadas }\end{array}$} & \multicolumn{2}{|c|}{$\begin{array}{c}\text { Demandas e } \\
\text { lutas dos MSR }\end{array}$} & \multicolumn{2}{|c|}{$\begin{array}{l}\text { Mulheres e MSR } \\
\text { contemporâneos }\end{array}$} & \multicolumn{2}{|c|}{$\begin{array}{c}\text { Ações socioeducativas dos } \\
\text { MSR }\end{array}$} \\
\hline \multicolumn{2}{|c|}{72 u.c.e's $=10 \%$ do total } & \multicolumn{2}{|c|}{312 u.c.e's $=45 \%$ do total } & \multicolumn{2}{|c|}{134 u.c.e's $=19 \%$ do total } & \multicolumn{2}{|c|}{181 u.c.e's $=26 \%$ do total } \\
\hline Palavras & $x^{2}$ & Palavras & $x^{2}$ & Palavras & $\mathrm{x}^{2}$ & Palavras & $\mathrm{x}^{2}$ \\
\hline Entrevistas & 0,55 & Terra & 0,28 & Mulher & 0,47 & Educação do campo & 0,40 \\
\hline Qualitativas & 0,42 & Agricultor & 0,20 & Gênero & 0,32 & Práxis & 0,20 \\
\hline Observação & 0,30 & Experiência & 0,18 & Rurais & 0,30 & Cidadania & 0,19 \\
\hline Etnografia & 0,26 & Cooperativismo & 0,15 & Sindicato & 0,25 & Pedagogia & 0,18 \\
\hline Semiestruturado & 0,25 & Projeto & 0,14 & Militância & 0,24 & Escola & 0,16 \\
\hline
\end{tabular}

Fonte: Autora (2015). 


\subsection{Classe 2 - Demandas e lutas dos movimentos sociais rurais}

A segunda classe da análise hierárquica aqui empregada envolve $45 \%$ do total, perfazendo 312 u.c.e's, o que corresponde a um alto poder explicativo pela sua representatividade na análise semântica. Portanto, esta é a classe com maior poder explicativo no estado da arte das pesquisas sobre movimentos sociais, dentre o conteúdo das demais classes do dendograma.

Os conteúdos da Classe 2 presentes nas palavras de maior associação foram: terra, assentamento, experiência, agricultor, cooperativismo, projeto e coletivo - termos relacionados às demandas materiais emergenciais do cotidiano das bases dos movimentos sociais rurais. Nesta classe, a "terra" constitui um dos elementos centrais a partir do qual deriva a atuação dos movimentos de resistência. Mas, se, por um lado, predominam movimentos sociais rurais que reivindicam a propriedade da terra, por outro, existem aqueles que lutam pelo uso sustentável da mesma.

Observou-se, assim, que "terra" e "luta" têm significados que são relacionais às experiências específicas dos sujeitos. Neste sentido, Martins (1989) assinala que as lutas dos movimentos sociais já não mais se voltam para a conquista do poder do Estado, mas contra o próprio poder, na medida em que reconhecem uma crise do Estado e do poder na sociedade atual.

\subsection{Classes 3 - Mulheres e movimentos sociais contemporâneos}

A Classe 3 foi composta por 134 u.c.e's, que correspondem a $19 \%$ do total, o que também demonstra um significativo poder explicativo. As palavras de maior associação nesta classe foram: mulher, gênero, rurais, empoderamento, sindicato e militância. Essa classe aponta para a emergência de estudos mais recentes que revelam a influência dos novos movimentos sociais e a participação da mulher camponesa nos mesmos. Tal fato se traduz em uma inovação das relações de poder nos movimentos sociais.
De acordo com Touraine (2002), os novos movimentos sociais passam a conviver com outros tipos de movimentos sociais, que têm um interesse menos utilitário e de maior reivindicação pelo direito de ser diferente. No entanto, eles não se isentam de posições tradicionais de desigualdades de gênero.

Neste sentido, a participação das mulheres nos movimentos sociais é, também, um espaço de luta, de contestação dos dispositivos de poder que organizam saberes dominantes, mas não deixa de ser uma possibilidade de escapar do controle familiar e de vivenciar outros códigos. Contudo, poucas mulheres estão ocupando cargos de liderança, o que demonstra certo conservadorismo no espaço de atuação das mulheres nos movimentos sociais rurais. Mesmo nos movimentos em que existe um estimulo à organização das mulheres, como o MST (Movimento dos Sem Terra), as questões de gênero ficam sempre em segundo plano quando relacionadas a outras questões da categoria, como as de ordem econômica.

Segundo Deere (2004), a falta de interesse dos movimentos sociais, principalmente no período de 1989 a 1993, em permitir o acesso formal da mulher à terra, se deve, em grande parte, à própria visão que os mesmos fazem da luta das mulheres, pois entendem que a sua participação pode provocar uma divisão do movimento e abalar os interesses coletivos. Por isso, as reivindicações das mulheres seriam tratadas a partir de uma questão de classe e não de gênero.

Na pesquisa intitulada Ação política, transformação social e reconstrução de identidades: um olhar a partir do feminismo para a militância das mulheres rurais nos movimentos sociais, a questão do reconhecimento da mulher "militante" surge como mecanismo central na dinâmica mobilizatória articulada pelas mulheres nos movimentos, pois implica em um complexo conjunto de relações e de jogos de poder. Se, por um lado, sob a alcunha de "doméstica", a condição essencialmente marginalizada se restringe ao espaço doméstico e é vivenciada por ela, por outro lado, a identidade de "militante" implica em um universo de 
relações que encontra ressonância em todas as esferas da vida cotidiana.

\subsection{Classe 4 - Ações socioeducativas dos movimentos sociais rurais}

A Classe 4 foi composta por 181 u.c.e $(26 \%$ do total) e os conteúdos lexicais mais explicativos para a pauta de demanda pelos movimentos sociais rurais foram: educação do campo, práxis, cidadania, pedagogia, escola e vivência. Os conteúdos representativos da Classe 4 fazem alusão às práticas educativas dos movimentos sociais no meio rural, em especial, as que se situam no campo do trabalho, da cooperação e da educação. Além disso, as pesquisas sobre movimentos sociais e educação do campo têm evidenciado um rico campo de investigação, com ênfase no processo de constituição desses movimentos e no saber gestado no cotidiano dessas lutas.

As pesquisas mostraram que a defesa, pelos movimentos sociais rurais, de uma educação do campo tem como sustentação o reconhecimento de uma realidade de trabalhadores e trabalhadoras que têm resistido para continuar produzindo sua vida no espaço rural, e, especialmente, o reconhecimento de que esta realidade precisa ser alterada, tendo em vista a crescente pobreza, o desemprego, as grandes desigualdades sociais e as dificuldades de acesso às políticas públicas (saúde, educação, transporte, infraestrutura etc.).

\subsection{Análise temporal das temáticas}

Para complementar as análises acerca das temáticas relativas aos "movimentos sociais rurais", foi realizada uma análise temporal, acerca das referidas temáticas, compreendendo o período de 1980 a 2015. O período em foco é significativo para os estudos sobre os movimentos sociais, pois se caracteriza como um momento no qual os movimentos sociais, rurais ou urbanos, modificaram seus modos de mobilização e demanda.

O recorte proposto para análise abarca a transição entre o fim da ditadura militar e o estabelecimento do regime democrático, no Brasil. A consideração dos anos 1980 para o início da análise se deveu, nomeadamente, pelo fato de que a criação do Movimento dos Trabalhadores Rurais se deu em 1984.

Nota-se, na Tabela 1, a abrangência e a diversidade temática que tem norteado as pesquisas relativas às práticas implementadas pelos movimentos sociais rurais. Essa constelação temática se ampliou a partir de 2003, com os governos Lula e Dilma, mais comprometidos com as bandeiras

Tabela 1. Temáticas abordadas nas dissertações e teses, nos períodos de 1980-2002 e de 2003-2015

\begin{tabular}{|c|c|c|c|c|}
\hline \multirow{2}{*}{ Temáticas } & \multicolumn{4}{|c|}{ Período } \\
\hline & $1980-2002$ & 2003- 2015 & Total & $\%$ \\
\hline $\begin{array}{l}\text { Relato das ações de enfrentamento implementadas pelos Movimen- } \\
\text { tos Sociais Rurais (Movimento sindical, trabalhista, Ligas Campone- } \\
\text { sas, MST, PT) }\end{array}$ & 8 & 28 & 36 & $28 \%$ \\
\hline Educação & 3 & 17 & 20 & $16 \%$ \\
\hline Gênero e juventude & 3 & 10 & 13 & $10 \%$ \\
\hline Trabalho, organização produtiva e desenvolvimento & 3 & 9 & 12 & $9 \%$ \\
\hline Sociabilidade, memória e identidade & 0 & 10 & 10 & $8 \%$ \\
\hline Agroecologia e ambiente & 0 & 9 & 9 & $7 \%$ \\
\hline Ação do Estado, direito e sistema penal & 0 & 8 & 8 & $6 \%$ \\
\hline Práticas comunicativas e uso de TICs & 0 & 8 & 8 & $6 \%$ \\
\hline Territorialização, desterritorialização e configuração do espaço & 0 & 6 & 6 & $5 \%$ \\
\hline Mídia & 0 & 2 & 2 & $2 \%$ \\
\hline Obra autoral & 1 & 1 & 2 & $2 \%$ \\
\hline Total & 18 & 108 & 126 & $100 \%$ \\
\hline
\end{tabular}

Fonte: Autora (2015). 
sociais que os anteriores. Assim, as pesquisas passaram a revelar o aparecimento e/ou o fortalecimento de temáticas relativas às questões de gênero e juventude; educação; territorialização e configuração do espaço; práticas comunicativas utilizadas pelos movimentos sociais rurais; meio ambiente; socialização, memória e identidade. $\mathrm{O}$ número de teses e dissertações sobre movimentos sociais rurais anteriores a 2003 foi inexpressivo, apesar da grande importância das Ligas Camponesas e do movimento sindical na década de 1950. Esta situação começou a se modificar a partir de 2003, quando houve um aumento significativo do número de produções relativas aos movimentos sociais.

Observando o período após 2002, verifica-se que, embora sobressaia a temática relativa à luta e resistência dos Movimentos Sociais Rurais, novas práticas e preocupações são retratadas nas pesquisas realizadas sobre estes movimentos. Percebe-se, através das pesquisas realizadas, que, para além da luta pela reforma agrária, passou a haver um direcionamento das ações dos movimentos sociais rurais na direção de um novo modelo de desenvolvimento agrícola, o agroecológico, além da preocupação com as práticas educativas e as questões de gênero e geração. Desta forma, as temáticas que marcaram as pesquisas sobre movimentos sociais rurais foram agrupadas em 10 eixos centrais, neste artigo, considerando-se as palavras-chaves dos resumos das teses e dissertações analisados:

1. Relato das ações de enfrentamento implementadas pelos Movimentos Sociais Rurais (Movimento sindical, trabalhista, Ligas Camponesas, MST): neste tópico, as pesquisas apresentam a trajetória dos movimentos sociais rurais, a sua organização e ação coletiva. Enfocam as transformações no tempo e no espaço, bem como evidenciam a entrada de novos atores na defesa de seus interesses. Além disso, destacam a importância das Ligas Camponesas, do sindicalismo rural e do Movimento dos Sem Terra como campo de disputa pela representação política dos trabalhadores rurais na conformação política dos movimentos sociais rurais. Os estudos de Martins (1981) e Medeiros (2001) também denotam esta cartografia de conflitos dos movimentos sociais e acrescentam que, para entender as lutas por terra no Brasil contemporâneo, deve-se levar em consideração o fato de que essas lutas, sob diversas formas, estiveram intimamente ligadas a vários processos sociais e políticos que marcaram a formação da sociedade brasileira.

A conotação das temáticas apresentadas na Tabela 1 mostra que, em 2003 e nos dez anos seguintes, houve uma mudança no direcionamento das ações coletivas dos movimentos sociais frente ao poder público, como o apontado por Sigaud (2002) e Rosa (2009). Na medida em que passaram a dialogar com as instâncias decisórias do Estado na busca por acesso a políticas públicas que contemplassem de forma mais eficiente a diversidade de seus interesses, os movimentos sociais passaram de um viés mais contestador para um viés de negociação e diálogo com o Estado, no sentido de buscar, além da defesa de interesses particulares, a transformação da vida social através de ações coletivas. Desta forma, de acordo com Gohn (2004), os movimentos sociais estão inscrevendo suas necessidades para além dos direitos sociais tradicionais (condições básicas de sobrevivência) e têm encaminhado novas demandas, especialmente as de natureza identitária. Além disso, as reivindicações dos movimentos sociais contemporâneos têm se direcionado para a busca de melhorias em suas condições de vida.

2. Educação: estas pesquisas sinalizam a função educativa dos movimentos sociais rurais e sua luta pela concretização de uma educação para o campo, que valorize os conhecimentos e a prática cotidiana do homem, como destacam os estudos de 
Vendramini (1997) e Caldart (2004). Esta temática revelou um expressivo aumento das pesquisas pós-2002.

3. Trabalho, organização produtiva e desenvolvimento: estas pesquisas retratavam as relações de trabalho nos movimentos sociais no que se refere à organização da produção, no sentido de tentar definir o lugar e o papel dos movimentos sociais nas dinâmicas de desenvolvimento. Considerando-se o panorama das temáticas apresentadas acima, verificou-se que a questão do desenvolvimento assumiu um lugar central nas pesquisas após a eleição do presidente Lula. Isto se deveu, principalmente, ao fato de o Estado, a partir de então, ter investido na implementação de políticas e programas de desenvolvimento territorial e local. Os estudos de Bergamasco e Norder (1996) e de Ibarra et al. (2002) apontam justamente para esta situação.

4. Gênero e juventude: estes estudos evidenciavam a forma como os movimentos sociais rurais incorporavam, na sua luta, a questão de gênero. Esta temática despontou nas pesquisas a partir do surgimento dos novos movimentos sociais encampados nas últimas décadas do século XX. A relação entre gênero e movimentos sociais denuncia a discriminação e a distribuição do "poder" na sociedade, inclusive dentro dos próprios movimentos sociais, como assinalaram os estudos de Deere (2004) e Castro (2008).

5. Territorialização, desterritorialização e configuração do espaço: estas pesquisas buscavam analisar a atuação dos movimentos sociais no espaço agrário a partir de uma abordagem marcada pela perspectiva de demarcação espacial das lutas dos movimentos sociais, como demonstrado nos estudos de Gonçalves (2001) e de Fernandes (2005). Foi perceptível o aumento referente a esta temática no período pós-ano 2000, em virtude do controle e da conquista de territórios por parte dos movimentos sociais rurais.

6. Agroecologia e ambiente: estas pesquisas discutiam os elementos centrais para a construção de um modelo produtivo que tenha como eixo central a agroecologia, com base na agricultura familiar e camponesa. Observou-se, no período pós-2000, a entrada de pautas ambientais no repertório de lutas (preservação ambiental, agroecologia, defesa da biodiversidade, conhecimento tradicional e culturas locais) dos movimentos sociais.

A temática da agroecologia apresentada nas pesquisas se caracteriza por destacar o modo de produzir e de viver no campo baseado nos conhecimentos adquiridos historicamente pelas comunidades tradicionais. No entanto, as pesquisas sobre esta temática ressaltam que, embora os movimentos camponeses brasileiros tenham incorporado, em suas pautas, questões ambientais, este ainda é um processo não totalmente definido, que está em vias de conformação. Segundo Borsatto e Carmo (2013), os movimentos sociais rurais, principalmente o MST, têm se apropriado da agroecologia como bandeira na luta pela reforma agrária, cuja atuação perpassa a dimensão produtiva e gera novos questionamentos políticos diante das transformações do espaço rural.

7. Ação do Estado, direito e sistema penal: são pesquisas que têm a pretensão de analisar a criminalização dos movimentos sociais e a consequente violência institucional presente no sistema de segurança pública. Neste contexto, o sistema penal exerce o controle social ao transformar conflitos que evidenciam problemas não supridos pelo aparelho estatal em crimes como forma de contenção. Neste sentido, o processo de criminalização dos movimentos sociais rurais mistura-se com outras estratégias adotadas pelas classes 
dominantes, como a cooptação e a violência, no sentido de bloquear as lutas sociais por direitos. Os estudos de Santos, Teixeira e Becker (2000) e de Bortolozzi (2008) já apontavam para esta situação de conflitualidade nos espaços sociais agrários, na medida em que a violência se apresentava mesclada com o processo de criminalização dos movimentos sociais rurais.

8. Sociabilidade, memória e identidade: estas pesquisas buscam analisar as práticas de socialização e sociabilidade entre os diversos atores sociais que participam dos movimentos sociais e que contribuem para a formação de uma memória coletiva do movimento, ou seja, a análise da complexa relação entre o vivido e as representações sobre o passado. Além disso, retratam também a carga cultural presente nestes movimentos, que pode ser traduzida através do apego às tradições, muito evidenciadas nas relações sociais da população, ou seja, refletem a identidade social da comunidade que reproduz o modo de vida do campo. Vários estudos na literatura sociológica já apontavam para estas questões, tais como Moraes e Silva (2004) e Comerford (1999).

9. Práticas comunicativas e uso de TICs: estas pesquisas abordam a importância da comunicação como ferramenta estratégica para os movimentos sociais e sua contribuição na ampliação do caráter educativo das pessoas no exercício da cidadania. A utilização das Tecnologias da Informação e Comunicação (TICs) destaca-se como uma característica atual dos movimentos sociais, principalmente depois dos anos 2000, devido a uma mudança organizativa desses movimentos junto às transformações da ordem mundial que apontam para uma arquitetura baseada na noção de rede. Os estudos de Scherer-Warren (1993) e de Canclini (2005) destacam justamente como esta faceta relativa à estra- tégia comunicativa dos movimentos sociais têm influenciado em suas práticas de mobilização e na construção de sua visibilidade.

10. Mídia: as pesquisas analisam as diferentes facetas do discurso midiático que, ao mesmo tempo em que contribui para a visibilidade dos movimentos sociais rurais na discussão sobre a questão agrária, pode também desqualificar e deslegitimar todo o repertório de ações gestadas por estes movimentos. Os estudos de Gonh (2000) e Comparato (2001) já mostravam uma dinâmica tensa e conflituosa expressa pela relação entre os movimentos sociais, sobretudo o MST, com o campo midiático, uma vez que os campos sociais possuem lógicas próprias de funcionamento.

Ao analisar os eixos temáticos centrais presentes nas dissertações e teses, constatou-se que a dimensão espacial, territorial e geopolítica dos movimentos sociais rurais traz pistas importantes para se pensar as múltiplas formas de manifestação política e de resistência dos movimentos sociais. O caráter de resistência se configura através da busca pela ampliação de direitos através da participação social, fundamentada na consolidação de uma concepção política crítica de mundo. Destaca-se, neste cenário, a emergência de novos atores sociais, como as mulheres e os jovens, tanto do ponto de vista de propostas que pautam os temas sociais da contemporaneidade, como na forma como se organizam, através da utilização dos meios de comunicação para se mobilizar e alcançar visibilidade. No entanto, vale ressaltar que a grande maioria dos trabalhos analisados traz leituras dos movimentos sociais relativas aos anos 1980 e 1990. No entanto, esta segunda década dos anos 2000, vai deixando cada vez mais nítida a forma como os movimentos sociais, inclusive no campo, adquirem caráter mais informal e menos nitidamente institucionalizado de atuação, com o avanço da utilização das redes de comunicação, tal como sugere Canclini (2005). 
Já no que se refere à concentração das publicações por região, verificou-se uma predominância de pesquisas nas regiões Sudeste $(57 \%)$, seguida pelas regiões Sul $(20 \%)$ e Nordeste (19\%), totalizando $96 \%$ dos trabalhos identificados. Já nas demais regiões (Norte e Centro-Oeste), as pesquisas sobre a temática dos movimentos sociais rurais foram inexpressivas, com poucas publicações no Centro-Oeste (4\%) e nenhuma publicação no Norte. Tal fato pode ser explicado em função das regiões Sudeste, Sul e Nordeste abrigarem um número elevado de Instituições de Ensino Superior (IES) de grande tradição em pesquisa no País, bem como programas de pós-graduação que trabalham com a temática dos movimentos sociais. Na contramão desta realidade, a escassez de publicações nas regiões Centro-Oeste e Norte provavelmente se deve ao fato dos programas de pós-graduação destas regiões serem recém-criados, por isso, não estão consolidados, principalmente na região Norte, onde a expansão da rede federal é recente.

As pesquisas realizadas em torno da temática relativa aos movimentos sociais rurais indicam tradição nas pesquisas, voltada para a dimensão fundiária e para os conflitos de terra nas regiões Sudeste, Sul e Nordeste. Os resultados da presente pesquisa apontaram, ainda, para o fato de terem sido poucas as universidades que apresentaram constância na investigação relativa aos movimentos sociais. Os estudos ficaram concentrados em quatro universidades: Unicamp, Universidade Federal de Viçosa (UFV), Universidade Federal de Santa Catarina (UFSC) e Universidade Federal do Ceará (UFC).

No que se refere aos autores mais referenciados nas 126 pesquisas analisadas sobre os movimentos sociais rurais, há um conjunto de pesquisadores brasileiros mencionados em, praticamente, todas elas. Constatou-se que, tomando como base uma perspectiva sociológica, José de Souza Martins é a referência central na discussão sobre as lutas sociais no campo e a expropriação do camponês. Aparecem, ainda, nestas pesquisas relativas aos movimentos sociais, autores como: Cândido Grzybowski, Ilse Scherer-Warren e
Maria da Glória Gohn. Já no campo da Educação, os autores mais citados são: Paulo Freire, Carlos Rodrigues Brandão e Roseli Salete Caldart. No que diz respeito, especificamente, ao Movimento dos Trabalhadores Sem Terra (MST), foram três as referências citadas em, praticamente, todas as investigações: Bernardo Mançano Fernandes, João Pedro Stédile e Roseli Salete Caldart. Quanto à definição de movimentos sociais, alguns autores estrangeiros foram referenciados, tais como: Alain Touraine, Alberto Melucci, Eric Hobsbawm e E. P. Thompson.

A análise relativa à concepção teórico-metodológica das pesquisas sobre movimentos sociais mostrou uma perspectiva interdisciplinar, com a aproximação entre áreas do conhecimento, como Sociologia, Ciência Política, Filosofia, Pedagogia, Economia, Geografia, História e Psicologia. A maioria das pesquisas adotou abordagem qualitativa, utilizando metodologias como a "história de vida", com enfoque direcionado à compreensão das intencionalidades do cotidiano dos trabalhadores rurais, com especial ênfase em suas representações sociais. Um aspecto observado foi a presença do pesquisador junto aos sujeitos da pesquisa. Muitos deles revelavam, nas pesquisas, a sua identificação com o processo de luta pela terra.

Um último aspecto a ser mencionado diz respeito ao fato de todas as pesquisas terem, como ponto de partida, uma reflexão mais geral sobre os movimentos sociais rurais para, de forma secundária, caracterizarem as relações locais que a envolviam. Desta forma, as teses e dissertações analisadas revelaram uma postura analítica marcada pelas críticas ao capitalismo e comprometidas com o empoderamento dos atores sociais do campo.

\section{Considerações finais}

A análise das dissertações e teses relativas aos movimentos sociais rurais no Brasil desde a década de 1980 aos dias atuais constatou indícios de novas configurações dos movimentos sociais no período posterior a 2003. O material 
bibliográfico analisado (teses e dissertações) mostra que, enquanto os movimentos sociais da década de 1980 até fins do século XX tinham as suas reivindicações focalizadas no mundo do trabalho, sendo a questão do acesso à terra o ponto fundamental das ações coletivas, os movimentos dos anos 2000 voltam-se de forma crescente para a vida cotidiana, com demandas relativas à Educação, ao uso dos meios de comunicação, bem como às questões relativas à juventude e às desigualdades de gênero. Desta forma, temas tradicionais nas pesquisas são recolocados e novos emergem a partir das novas dinâmicas dos movimentos sociais no meio rural.

Neste sentido, as ações coletivas que os movimentos sociais rurais têm assumido, na atualidade, são distintas daquelas vigentes entre as décadas de 1980 e fins do século XX. As dissertações e teses pesquisadas evidenciam novos direcionamentos incorporados nas ações coletivas dos movimentos sociais em curso nos anos 2000, que apontam para uma politização de aspectos relativos à vida privada. As teses e dissertações defendidas nos programas de pós-graduação no Brasil, no período entre 2003 e 2015, correspondente aos governos Lula e Dilma, demonstram, enfim, que a ação coletiva dos movimentos sociais rurais avança de forma crescente para questões relativas às condições de vida das pessoas e para o reconhecimento dos direitos de novos atores sociais, como as mulheres e os jovens.

Percebe-se, assim, através das teses e dissertações analisadas, que os movimentos sociais não existem enquanto um modelo estático de conduta coletiva, mas em cada período, os conflitos e as reivindicações seguem tendências e formatos diferentes, ou seja, são capazes de se metamorfosear. $\mathrm{O}$ estado da arte evidenciou mudanças nas ações coletivas dos movimentos sociais ao longo do período analisado, com a configuração de novas reivindicações mais voltadas para as condições de vida da família e para o uso de novos instrumentos de ação política, como a utilização dos meios de comunicação que tendem, ao que parece, a tornar a direção dos movimentos sociais mais fluida e menos centralizada.
Além disso, as pesquisas analisadas denunciam fatos e apontam caminhos para a emancipação, a tomada de consciência, a autonomia e a organização coletiva dos movimentos sociais no espaço rural. Por fim, a notável conclusão é que o aumento das pesquisas sobre os movimentos sociais rurais nasce, não só do engajamento ou da sensibilidade dos estudiosos do tema com as questões sociais, mas também das próprias urgências e demandas da realidade sob estudo, uma vez que as experiências realizadas pelos movimentos sociais rurais, instituídos ou não, vêm ganhando força sociocultural e acadêmica nos diferentes estados brasileiros.

\section{Referências}

BERGAMASCO, S. M. P. e NORDER, L. A. C. A alternativa dos assentamentos rurais: organização social, trabalho e política. São Paulo: Terceira Margem, 2003.

BIANCHA, C. A. et al. O estado da arte da pesquisa sobre o fracasso escolar (1991-2002): um estudo introdutório. Educação e Pesquisa, n. 1, p. 51-72, 2004.

BORSATTO, R. S. e CARMO, M. S. do. A construção do discurso agroecológico no Movimento dos Trabalhadores Rurais Sem-Terra (MST). Rev. Econ. Sociol. Rural, Brasília, v. 51, n. 4, p. 645-660, dez. 2013.

BORTOLOZZI, A criminalização dos movimentos sociais como obstáculo à consolidação dos direitos fundamentais. Curitiba: UFPR, 2008.

CALDART, R. S. Movimento dos Sem Terras: reflexões sobre a Pedagogia da Terra. Revista de Educação, CEAP, Salvador/Bahia, ano 12, p. 21-35, set. /nov. 2004.

CANCLINI, N. G. Diferentes, desiguais e desconectados. Rio de Janeiro: Editora UERJ, 2005.

CASTRO, E. G. Juventud, generación, y prácticas políticas: procesos de construcción de la categoría juventud rural como actor político. Revista Argentina de Sociología, v. 11, p. 50-65, 2008.

COHEN, J. L.; ARATO, A. Los movimentos sociales y la sociedad civil. In: Sociedad civil y teoria politica. México: Fondo de Cultura Economica, 2000, p. 556-635.

COMERFORD, J. Fazendo a luta: sociabilidade, falas e rituais na construção de organizações camponesas. Rio de Janeiro: Relume Dumará, 1999. 
COMPARATO, B. K. A ação política do MST. São Paulo em Perspectiva, São Paulo, v. 15, n. 4, p. 105-118, out./ dez. 2001.

DEERE, C. D. Os direitos da mulher à terra e os movimentos sociais rurais na reforma agrária brasileira. Revista Estudos Feministas, CFH/CCE Universidade Federal de Santa Catarina (UFSC), v. 12, n. 1, p. 175-204, 2004.

FERNANDES, B. M. Movimentos socioterritoriais e movimentos socioespaciais: contribuição teórica para uma leitura geográfica dos movimentos sociais. Revista NERA, ano 8, n. 6, p. 59-74, 2005.

FERREIRA, N. S de A. As pesquisas denominadas "estado da arte". Revista Educação e Sociedade, Campinas, CEDES, n. 79, p. 257-272, 2002.

GOHN, M. G. Empoderamento e participação da comunidade em políticas sociais. Saúde e Sociedade, São Paulo, v. 13, n. 2, p. 20-31, maio/ago. 2004.

GONÇALVES, C. W. P. Geografias: movimientos sociales, nuevas territorialidades y sustentabilidad. México: Siglo Veintiuno, 2001.

GRZYBOWSKI, C. A Comissão Pastoral da Terra e os colonos do sul do Brasil. In: PAIVA, V. (Org.) Igreja e questão agrária. São Paulo: Loyola, 1994, p. 248-276.

IBARRA, P., GOMÀN, R., GONZALEZ, R. e MARTÍ, S. Movimientos sociales, políticas públicas y democracia radical: algunas cuestiones introductorias. In: IBARRA, P., MARTÍ, S. e GOMÀN, S. (Coords.). Creadores de la democracia radical: movimientos sociales y redes de políticas públicas. Barcelona: Icaria Editorial, 2002, p. 9-22.

MARTINS, J. S. Os camponeses e a política no Brasil: as lutas sociais no campo e seu lugar no processo político. Petrópolis: Vozes, 1981.

Caminhada no chão da noite: emancipação política e libertação nos movimentos sociais do campo. São Paulo: HUCITEC, 1989.

MEDEIROS, L. S. "Sem terra", "assentados", "agricultores familiares": considerações sobre os conflitos sociais e as formas de organização dos trabalhadores rurais brasileiros. In: ¿Una nueva ruralidad en América Latina? Buenos Aires: CLACSO, 2001.

MELUCCI, A. A invenção do presente: movimentos sociais nas sociedades complexas. Petrópolis: Vozes, 2001.
MINAYO, M. C. de S. O desafio do conhecimento: pesquisa qualitativa em saúde. 4. ed. São Paulo: HUCITEC, 1996.

MORAES e SILVA, M. A de. A luta pela terra: experiência e memória. São Paulo: UNESP, 2004.

NAVARRO, Z. Democracia, cidadania e representação: os movimentos sociais rurais no Estado do Rio Grande do Sul, Brasil (1978-1990). In: NAVARRO, Z. (Org.). Política, protesto e cidadania no campo. Porto Alegre: Editora da Universidade/UFRGS, 1996, p. 62-105.

PAOLI, M. C. e TELLES, V. S. Direitos sociais: conflitos e negociações no Brasil contemporâneo. In: ALVAREZ, S., DAGNINO, E. e ESCOBAR, A. Cultura e politica nos movimentos sociais latino-americanos: novas leituras. Belo Horizonte: Ed. UFMG, 2000, p. 103-148.

PICOLOTTO, E. L. Processos de diferenciação dos movimentos sociais do campo no Sul do Brasil: identidade, articulação política e projeto. Raizes, Revista de Ciências Sociais e Econômicas, Campina Grande, v. 26, n. 1 e 2, p. 46-58, 2007.

REINERT, M. Alceste, une méthodologie d'analyse des données textuelles et une application. In: DE NERVAL, A. de G. Bull Methodol Sociol, v. 26, p. 24-54, 1990.

RICCI, R. A trajetória dos movimentos sociais no campo: história, teoria social e práticas de governos. Revista Espaço Acadêmico, Maringá/PR, ano V, n. 54, p. 1-5, nov. 2005.

SANTOS, J. V. T., TEIXEIRA, A. N. e BECKER, F. T. G. Conflitualidade e violência nos espaços agrários do Brasil contemporâneo. Revista Crítica de Ciências Sociais, n. 57-58, p. 147-168, jul./nov. 2000.

SCHERER-WARREN, I. Redes de movimentos sociais. São Paulo: Edições Loyola, 1993.

Para uma metodologia de pesquisa dos movimentos sociais e educação no campo. In: MOLINA, M. M. (Org.). Educação do campo e pesquisa: questões para reflexão. Brasília: Ministério do Desenvolvimento Agrário, 2006, p. 117-132.

SIGAUD, L. Lonas e bandeiras em terras pernambucanas. Rio de Janeiro: UFRJ, 2002.

TOURAINE, A. Poderemos viver juntos? Iguais e diferentes. 2. ed. Petrópolis: Vozes, 2003.

. Um novo paradigma: para compreender o mundo de hoje. Petrópolis: Vozes, 2006. 
